\title{
Perceptions and experiences of healthcare providers and beneficiaries on the National health insurance scheme of Rashtriya Swasthya Bima Yojana (RSBY) in a Taluk of South Indian State of Karnataka
}

\author{
Manaswitha Boyanagari*, Vamsi Krishna Boyanagari \\ Department of Public Health, Manipal University, Manipal, Karnataka, India
}

\section{A R T I C L E I N F O}

\section{Keywords:}

Below poverty line

Health insurance

RSBY

\begin{abstract}
A B S T R A C T
Background: Rashtriya Swasthya Bima Yojana (RSBY) was launched by the government of India on 1st April 2008 to provide BPL families of unorganized work sectors with access, choice, and, financial-risk protection for inpatient healthcare. The objective of the present study is to recognize the pros and cons by understanding the current process of RSBY implementation in Udupi Taluk of Karnataka State.

Material and methods: Qualitative research method was followed. An in-depth interview was the main tool of data collection from beneficiaries and service providers. The collected information was analyzed in a thematic manner.

Results: Factors that inhibit service utilization from beneficiaries' perspective were rejection from the hospitals, lack of awareness, and availability of fewer services. Acceptance by the hospital is one of the main factors that is encouraging the service utilization. From providers' perspective satisfaction of certain bona fides through the scheme was driving the service delivery. Negative aspects include No reimbursement and No proper guidelines from State Government.

Conclusion: Delay and uncertainty in the payment of claims by the insurance companies is the major reason informed by the hospitals for not providing treatment to the card holders. For people to gain back the confidence in the government schemes like RSBY, these concerns like delay in reimbursements, lack of awareness, fewer services, etc. reported would have to be addressed as the progress towards universal health coverage is hindered by negative perceptions impacting the trust in the RSBY. There is an urgent need to address this issue for RSBY to maintain its credibility.
\end{abstract}

\section{Introduction}

Indian government spends about $1 \%$ of its GDP on public health expenditure making the health system most heavily dependent on patients out of pocket expenditure. ${ }^{1}$ The Public health care system in India suffers from inadequate funds which results in poor infrastructure, lack of quality care and accessibility for large sections of the rural population. These situations often force the poor to prefer highly expensive private healthcare causing significant out-of-pocket expenditure. ${ }^{2}$ According to National Sample Survey Organization (NSSO) data 6 percent of the patients do not seek public/private health care as hospitalization is unaffordable and about 25to 40 percent patients have to sell their meagre assets or borrow money to meet their hospitalization expenses. ${ }^{3}$ Negative impact on demand for health care, contribution to household poverty, inequalities and little revenue generation are some of the well documented implications of out of pocket health expenditure. ${ }^{4}$ Studies on informal sector workers reveal that health shocks are the common form of household crisis. ${ }^{5}$ To achieve Universal Health Coverage the Government of India launched Rashtriya Swasthya Bima Yojana in the year 2008, a bottom-up approach, envisaging coverage for the BPL population as a first step. ${ }^{6}$ The scheme has rapidly expanded across India to cover inpatient benefits for more than 142 million workers from unorganized sector. ${ }^{7}$ Since April 1st, 2015, the RSBY scheme has been transferred to the Ministry of Health and Family Welfare. As per the sharing ratio both the State Government (25\%) and Central Government $(75 \%)$ pay the premium cost of the enrolled beneficiaries, to the insurance company selected by the State Government through competitive bidding process.

\subsection{Benefits}

Under RSBY the beneficiaries are entitled to hospitalization

\footnotetext{
* Corresponding author at: Madhav Nagar, Manipal, 576104, Karnataka, India.

E-mail address: manuboyanagari@ymail.com (M. Boyanagari).
} 
coverage of Rs. 30,000/- per annum on family floater basis covering most of the listed diseases in the package list which require hospitalization (inpatient services). Pre-existing disease conditions are covered from day one and there is no age limit. The scheme covers maximum of five members in the family which includes Head of the family, spouse and three dependents. Additionally, Rs. 1000/- is given per year per family, divided into Rs. 100/- per hospitalization to cover the transportation charges. ${ }^{1,6,8}$

\subsection{Enrolment process}

The Planning Commission of the Government of India houses the mechanism of defining the poor in India. At the State level the beneficiaries are identified according to the information included in the BPL list prepared by the State Government revenue/food/civil supplies departments. The State Government appoints a State Nodal Agency (SNA) that takes the responsibility for implementing, monitoring and part financing of the scheme.The list of BPL households given by the state government is transferred to the Central Government which then assigns a Unique Reference Number (URN) for each beneficiary family. This data is transmitted to the insurance company selected through competitive bidding by the State Government. The insurance company is responsible for preparing the enrolment plan through consultation with the relevant district authorities. Public and private hospitals in the district sign a contract with the insurance company.

These contracted hospitals are known as Empanelled hospitals which provide the inpatient services for the enrolled beneficiaries. The insurance companies take the responsibility for enrolling the beneficiaries, Information Education and Communication, installation of required IT facilities in the empanelled hospitals, settling the claims by the empanelled hospitals, and monitoring the behavior of the hospitals. ${ }^{1,5,6,8}$

As per the enrolment plan, the beneficiaries are enrolled at the village level enrolment stations and the process involves taking of one photograph of the head of the family and the whole family along with the finger prints of each family member of the listed beneficiary family. The beneficiary must pay an amount of Rs. 30/- during the enrolment process as registration fee and the printed smart cards are then handed over to the beneficiary family. $1,5,6,8$

\section{Objective}

In any Universal Health Coverage reform, communities are the main beneficiaries' and it is highly important to consider their preferred design features to maintain the sustainability and acceptability. (3) The objective of the present study is to recognize the pros and cons by understanding the current process of RSBY implementation in Udupi Taluk of Karnataka State. It is also important to study the perceptions and experiences of RSBY among service providers as this helps in identifying the factors that encourage or prevent service delivery from providers' perspective.

\section{Methods}

A Cross-sectional study was conducted in the rural village Panchayats of Badagabettu and Alevooru in Udupi taluk from January 2016 to June 2016. Qualitative approach to research was followed, in depth interviews were done among the participants. Ethical clearance was obtained from the Institutional Ethics Committee. Participants included in the study were the beneficiaries and the providers of RSBY scheme. Purposive sampling was done among RSBY cardholders aged above 18 years of age and chief of empanelled hospital were interviewed. Modified RSBY facility survey questionnaire and post hospitalization survey questionnaire were used to interview the beneficiaries. Informed consent was obtained from the participant to record the indepth interviews. The study included 22 beneficiaries and one public health care provider, these participants were interviewed. Information collected from the participants were transcribed. Coding was done and matched into various themes for the write-up.

\section{Results}

There are six empaneled hospitals in Udupi Taluk, one public hospital and other being private.

\subsection{Factors that inhibit service utilization from beneficiaries' perspective are as follow}

\subsubsection{Rejection from the hospitals}

Majority of the interviewed BPL households reported that they were rejected by the hospitals due to unknown reasons when approached for necessary treatment. People also reported that they didn't use the card because they heard from their friends about the rejection.

"My daughter always had a headache, so we went to 'hospital C' for a check-up and said I have this card but they said that you would not get any benefits. I don't know where we should go," at hospital A" also they said it's not acceptable, and we went to "hospital D", here also they said it's not acceptable. What should I do with this now?" (BPL Interviewee 19, Pragathi Nagar)

\subsubsection{Lack of awareness}

The interviewed BPL households reported that they were informed about the enrolment by the Village Panchayat through an announcement, but it did not reach people residing at far-flung places. The community members who heard the news informed their friends and relatives.

"I heard from others that Panchayat announced it, but many people living in faraway places do not know about it. I told to some people in my neighborhood about this; it's not possible for me to inform everyone. So the society has to take care about this. They have to inform people who come to take ration making sure everyone gets the information."(BPL Interviewee 1, Rajeev Nagar)

Although a booklet with information about the empaneled hospitals was given during the time of enrolment, many of the interviewed BPL households reported that proper information was not given regarding the benefits of the scheme and that they know the card gives RS. $30,000 /-$ benefits which can be used during serious illness only when admitted to a hospital. Most of them were either illiterate or poor literate and were unable to read/to understand the contents of the booklet.

"They did not give clear information about this card; they said everyone should come and register to enjoy the benefits. As everyone in the community approached, I went along with them. We didn't get any clear information. After that, no one spoke about this. I asked for twice about the benefits one person said that he didn't get any benefits." (BPL Interviewee 16, Pragathi Nagar)

“I didn't go to any hospital. I took the photo for the card and kept it in the house. They said everything is written in the booklet but I don't know how to read, so I didn't see that." (BPL Interviewee 14, Pragathi Nagar)

\subsubsection{Fewer services}

Most of the beneficiaries reported that during enrolment they were informed that they could use the card only for inpatient services. So they did not use the card as they were not seriously ill and did not get admitted as inpatients in the hospitals.

"I didn't use this scheme because we can only use this when the health is too bad and cannot use this for smaller problems." (BPL 


\section{Interviewee 3, Rajeeva Nagar)}

"Nobody in my house got admitted to the hospital, so we didn't use this card. The benefits are available only when we get admitted but not on OPD basis." (BPL Interviewee 18, Pragathi Nagar)

\subsubsection{Negative aspects}

Majority of the people reported that they enrolled under the scheme with the hope that the government scheme would help them during illness but the process of enrolment was strenuous and cumbersome due which they have to forego their work pay. Added to this they reported that they were rejected by the hospitals and the card was not useful.

"I stood in the queue for getting the card, you should have seen how difficult it was for us to stand in a rush for hours together, we took leave from work, we had no food for that day, and I lost the pay for the day, but it was not at all useful." (BPL Interviewee 15, Pragathi Nagar)

"We are BPL people, with the hope that we will be benefitted we took leave from work on the loss of wage, stood in the line for hours together but we didn't get any benefits. People who have misled us with a wrong picture are to be blamed" (BPL Interviewee 19, Pragathi Nagar).

\subsection{Factors that boost up service utilization from beneficiaries' perspective were identified as follows}

\subsubsection{Acceptance by the hospital}

During the interview one of the BPL family reported that they had utilized the scheme benefits. Their hospital bills were partly reimbursed after getting admitted to the hospital upon the advice of the hospital staff although the admission was not required in the case.

"Six months back my husband had undergone an eye operation, the "hospital A," asked us to pay Rs 15,000/- as a single payment. They said that if you have RSBY card, the hospital bill can be paid using that. We got my husband admitted to the hospital because they said benefits would be available only if we get admitted. I had the card, so they gave the treatment of Rs 6000 for free and said you would get free treatment for the next time too if you get this card.' (BPL Interviewee 17, Pragathi Nagar)

\subsubsection{Positive perceptions}

Majority of the people interviewed reported that they enrolled in the scheme with the belief that it will be useful during hospitalization to pay the bills. They reported that they are happy since it is sponsored by the government and would renew the scheme for the next year only when the said benefits are made available.

"It's good for BPL people; it is useful for many people because if we go to big hospitals the costs are so much and if we have this card that's a good facility I believe." (BPL Interviewee 1, Rajeev Nagar)

"We need the benefits of the card because if we get some help from the government, we will be happy." (BPL Interviewee 13, Alevooru)

\subsection{Factors that encourage service delivery from providers' perspective are as follow}

\subsubsection{Satisfying bona fides}

"It's a good scheme. I think it is a good programme it will be helpful for poor people who can't pay to the hospital so it will be very helpful. There are not many cases of RSBY in our hospital because we don't collect any charges, so everything is free for BPL candidates and pregnant patients. So there are little cases of RSBY after this I think I want to get advantages from RSBY. ....it will be advantageous for the hospital, so we are getting empaneled on our own" (Healthcare Provider interviewee 1, Public Hospital)

So it is evident from the interview of service provider that getting empaneled under the scheme is considered to satisfy certain bona fides

\subsection{Factors that prevent service delivery from providers' perspective are as follows}

\subsubsection{No reimbursement}

From the provider's interview, it is clearly evident that the major reason for lack of interest towards the provision of services and turning blind to the cardholders is the denial of reimbursement amount by the insurance companies.

"I heard in the meeting that private hospitals are not getting the RSBY claim back, so they have stopped since October 2015, so I came to know that only they are settling old cases since October 2015 they should not do like that right? Other insurance schemes are going well why RSBY is not going well because 'insurance bank $\mathrm{A}^{\prime}$ is not ready to pay. They are denying, and this should be rectified. Compared to other schemes RSBY is lagging behind" (Healthcare Provider interviewee 1, Public Hospital)

\subsubsection{No proper guidelines from the State Government}

No stipulated guidelines regarding the implementation of the scheme from the state government is also a discouraging factor revealed from the interview of one of the service providers as stated below.

"I think there are no guidelines from the government to get empaneled for RSBY, but it will be advantageous for the hospital, so we are getting empaneled on our own. So there is no direction, compulsion from the government that we should get empaneled with RSBY." (Healthcare Provider interviewee 1, Public Hospital)

\section{Discussion}

This study was set to explore both service providers and communities' experiences to understand the perceptions regarding RSBY. This section discusses the main findings and their implications on RSBY. From the providers' experiences delays in the reimbursement from the insurance companies for the services provided is a major concern that is hindering the service provider. Beneficiaries faced rejections from the empaneled hospitals and had to incur hospital expenditure from their own pocket. It was clear that there was a wide range of dissatisfaction in the community with the rejecting behavior of the empaneled hospitals. Although the official website of RSBY showed the hospital status as empaneled majority of the approached empaneled hospitals reported that they have de empaneled their hospital due to delay in reimbursements and that the official website is not updated. As such rejection by the Healthcare Providers to participate in the study due to their own reasons made the study confine to single provider's perspective. A study by David M. Dror \& Sukumar Vellakkal ${ }^{9}$ discussed that for RSBY, budgetary allocations are the major constraints in achieving its objective. Although the Village Panchayat and the Insurance companies played an important role in creating awareness, the level of awareness among the community members regarding the benefits of the scheme remained discouraging. Majority of the beneficiaries were either poorly literate or illiterate to understand the contents given in the information booklet about the scheme. People reported that they were not aware of benefits of RSBY in detail as well that the scheme need be renewed each year. The community members had taken initiative in spreading the awareness regarding the scheme to their friends and relatives because the information about the enrolment camp did not reach people residing in remote areas. A similar study by KS Nair et al. ${ }^{3}$ conducted in Delhi informed that for BPL families information in the pamphlet was 
difficult to read due to small letters resulting in a poor positive response. This shows that it is important to formulate strategies to increase the awareness of the scheme and engage them as a driving force to achieve Universal Health Coverage. Beneficiaries reported that a week was assigned to the enrolment camp which was not sufficient resulting in a strenuous process due to heavy rush. Also, some of them reported that they did not avail the services because they were not admitted to the hospital. Experience suggests that during implementation even the most carefully designed program will encounter difficulties ${ }^{4}$ According to a recent review by Forgia G La and Nagpal $S{ }^{10}$ the effects of health insurance in low- and middle-income countries shows that insurance can positively influence access and utilization of health services, provide financial protection against catastrophic health shocks while reducing out-of-pocket spending, and, if designed in a proper manner, offer greater benefits to the poor. Low enrolment rate and access to healthcare, lack of awareness and poor utilization are the much-recorded challenges that the scheme is facing ${ }^{7}$ Nevertheless, beneficiaries were ready to renew the scheme for the next year provided that they are given the outpatient benefits. The only reason for the beneficiaries to get enrolled under the scheme is that it is sponsored by the government and the hope that benefits can be availed during illness.

\section{Conclusion}

In conclusion, the major reason for the hospitals to reject the card holders is the delay and uncertainty in the payment of claims by the insurance companies. There is an urgent need to address this issue for RSBY to maintain its credibility. Beneficiaries faced rejections from the empaneled hospitals and had to incur hospital expenditure from their own pocket. The enrolled people were not aware of benefits in detail and that the scheme should be renewed each year. This shows that there is a need for the concerned authorities to formulate strategies to increase the awareness of the scheme so that acceleration in the utilization of services can be achieved. Addressing these challenges will promote confidence in RSBY thus making it more likely to scale up, also beyond BPL and be sustainable, increasing access achieving universal health coverage.

\section{References}

1. Wu Q. What Cause the Low Enrolment Rate and Utilization of Rashtriya Swasthya Bima Yojana: A Qualitative Study in Two Poor Communities in India. Liverpool School of Tropical Medicine; 2012. Available from: http://www.chsj.org/uploads/1/0/2/1/ 10215849/what_cause_the_low_enrolment_rate_and_utilization_of_rashtriya_swasthya_ bima_yojna.pdf.

2. Gill HS, Shahi AK. Rashtriya swasthya bima yojna in India- implementation and impact. Int J Multidiscip Res. 2012;2(5):155-173.

3. Nair KS, Raj S, Tiwari VK. Rashtriya Swasthya Bima Yojana (RSBY)-hospitalised families in National Capital Territory of Delhi. Artha Vijnana J Gokhale Inst Polit Econ. 2013;55(1):71. Available from: http://www.i-scholar.in/index.php/ArthaVij/article/ view/111196.

4. Mulupi S, Kirigia D, Chuma J. Community perceptions of health insurance and their preferred design features: implications for the design of universal health coverage reforms in Kenya. BMC Health Serv Res. 2013;13:1-12.

5. Berg E, Ghatak M, Manjula R. Economic Organisation and Public Policy Discussion Paper Implementing Health Insurance For The Poor: The Rollout of Rsby In Karnataka Rajasekhar and Sanchari Roy for The Poor. 2011; 2011. (March). Available from: http://sticerd.lse. ac.uk/dps/eopp/eopp25.pdf.

6. Nagpal S. Expanding Health Coverage for Vulnerable Groups in India. World Bank's Univers Heal Cover Stud Ser. vol. 13. 2013; 2013:1-40. Available from: http:// documents.worldbank.org/curated/en/2013/01/17207220/expanding-healthcoverage-vulnerable-groups-india.

7. Rathi P, Mukherji A, Sen G, Rashtriya Swasthya Bima Yojana. Evaluating utilisation, roll-out and perceptions in Amaravati district, Maharashtra. Econ Polit Wkly. 2012;xlvii(39):57-64. Available from: http://www.indiaenvironmentportal.org.in/ files/file/RashtriyaSwasthyaBimaYojana.pdf.

8. Rashtriya Swasthya Bima Yojana. 2016; 2016. [cited March 14]. Available from: http:// www.rsby.gov.in/about_rsby.aspx.

9. Dror DM, Vellakkal S. Is RSBY India's platform to implementing universal hospital insurance? Indian J Med Res. 2012;135(1):56-63.

10. La Forgia G, Nagpal S. Government-Sponsored Health Insurance in India: Are You Covered? 2012; 2012:1-446. Available from: https://openknowledge.worldbank. org/bitstream/handle/10986/11957/722380PUBOEPI008029020120Box367926B. pdf? sequence $=1 \&$ isAllowed $=\mathrm{y}$. 